NASA/TM-2003-212096

\title{
Comparisons of Gas-Phase Temperature Measurements in a Flame Using Thin-Filament Pyrometry and Thermocouples
}

Peter Struk and Daniel Dietrich

Glenn Research Center, Cleveland, Ohio

Russell Valentine and Ioan Feier

Case Western Reserve University, Cleveland, Ohio 
Since its founding, NASA has been dedicated to the advancement of aeronautics and space science. The NASA Scientific and Technical Information (STI) Program Office plays a key part in helping NASA maintain this important role.

The NASA STI Program Office is operated by Langley Research Center, the Lead Center for NASA's scientific and technical information. The NASA STI Program Office provides access to the NASA STI Database, the largest collection of aeronautical and space science STI in the world. The Program Office is also NASA's institutional mechanism for disseminating the results of its research and development activities. These results are published by NASA in the NASA STI Report Series, which includes the following report types:

- $\quad$ TECHNICAL PUBLICATION. Reports of completed research or a major significant phase of research that present the results of NASA programs and include extensive data or theoretical analysis. Includes compilations of significant scientific and technical data and information deemed to be of continuing reference value. NASA's counterpart of peerreviewed formal professional papers but has less stringent limitations on manuscript length and extent of graphic presentations.

- TECHNICAL MEMORANDUM. Scientific and technical findings that are preliminary or of specialized interest, e.g., quick release reports, working papers, and bibliographies that contain minimal annotation. Does not contain extensive analysis.

- CONTRACTOR REPORT. Scientific and technical findings by NASA-sponsored contractors and grantees.
- CONFERENCE PUBLICATION. Collected papers from scientific and technical conferences, symposia, seminars, or other meetings sponsored or cosponsored by NASA.

- SPECIAL PUBLICATION. Scientific, technical, or historical information from NASA programs, projects, and missions, often concerned with subjects having substantial public interest.

- TECHNICAL TRANSLATION. Englishlanguage translations of foreign scientific and technical material pertinent to NASA's mission.

Specialized services that complement the STI Program Office's diverse offerings include creating custom thesauri, building customized databases, organizing and publishing research results ... even providing videos.

For more information about the NASA STI Program Office, see the following:

- Access the NASA STI Program Home Page at http://www.sti.nasa.gov

- E-mail your question via the Internet to help@sti.nasa.gov

- Fax your question to the NASA Access Help Desk at 301-621-0134

- Telephone the NASA Access Help Desk at 301-621-0390

- Write to:

NASA Access Help Desk

NASA Center for AeroSpace Information 7121 Standard Drive

Hanover, MD 21076 
NASA/TM-2003-212096

AIAA-2003-853

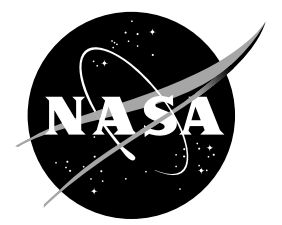

\section{Comparisons of Gas-Phase Temperature Measurements in a Flame Using Thin-Filament Pyrometry and Thermocouples}

Peter Struk and Daniel Dietrich

Glenn Research Center, Cleveland, Ohio

Russell Valentine and Ioan Feier

Case Western Reserve University, Cleveland, Ohio

Prepared for the

41st Aerospace Sciences Meeting and Exhibit

sponsored by the American Institute of Aeronautics and Astronautics

Reno, Nevada, January 6-9, 2003

National Aeronautics and

Space Administration

Glenn Research Center 


\section{Acknowledgments}

The authors acknowledge the NASA Office of Biological and Physical Research (OBPR), the Graduate Student Researchers Program (GSRP), the Ohio Aerospace Institute (OAI), and the National Center for Microgravity

Research (NCMR) for their support of this research.

Available from

NASA Center for Aerospace Information 7121 Standard Drive

Hanover, MD 21076
National Technical Information Service 5285 Port Royal Road Springfield, VA 22100

Available electronically at http:/ /gltrs.grc.nasa.gov 


\title{
COMPARISONS OF GAS-PHASE TEMPERATURE MEASUREMENTS IN A FLAME USING THIN-FILAMENT PYROMETRY AND THERMOCOUPLES
}

\author{
Peter Struk and Daniel Dietrich \\ National Aeronautics and Space Administration \\ Glenn Research Center \\ Cleveland, Ohio 44135
}

Russell Valentine and Ioan Feier*

Case Western Reserve University

Cleveland, Ohio 44106

\begin{abstract}
$\underline{\text { Abstract }}$
Less-intrusive, fast-responding, and full-field temperature measurements have long been a desired tool for the research community. Recently, the emission of a silicon-carbide ( $\mathrm{SiC}$ ) fiber placed in a flowing hot (or reacting) gas has been used to measure the temperature profile along the length of the fiber. The relationship between the gas and fiber temperature comes from an energy balance on the fiber. In the present work, we compared single point flame temperature measurements using thin-filament pyrometry (TFP) and thermocouples. The data was from vertically traversing a thermocouple and a $\mathrm{SiC}$ fiber through a methanol/air diffusion flame of a porous-metal wick burner. The results showed that the gas temperature using the TFP technique agreed with the thermocouple measurements $(25.4 \mu \mathrm{m}$ diameter wire) within $3.5 \%$ for temperatures above $1200 \mathrm{~K}$. Additionally, we imaged the entire $\mathrm{SiC}$ fiber (with a spatial resolution of $0.14 \mathrm{~mm}$ ) while it was in the flame using a high resolution CCD camera. The intensity level along the fiber length is a function of the temperature. This results in a one-dimensional temperature profiles at various heights above the burner wick. This temperature measurement technique, while having a precision of less than $1 \mathrm{~K}$, showed data scatter as high as $\pm 38 \mathrm{~K}$. Finally, we discuss the major sources of uncertainty in gas temperature measurement using TFP.
\end{abstract}

\section{Introduction}

The ideal gas-phase temperature measurement is a full-field measurement with good spatial resolution, is accurate, has a fast response time, is non-intrusive, has wide dynamic range, and is easy to apply. Thinfilament pyrometry (TFP) is a technique that meets several of the above characteristics especially for higher temperature applications like combustion. TFP uses a thin-filament that is typically on the order of 10 to 100 microns in diameter. Silicon-Carbide, or SiC, has emerged as a material with suitable properties for TFP: good strength even at flame temperatures, relatively constant emissivity, resistant to oxidation and catalytic effects, and widely available. When used for temperature measurements, the $\mathrm{SiC}$ fiber is placed in a thermal environment which heats the SiC. Subsequently, the SiC emits thermal gray body radiation, which is then detected, quantified, and related to the temperature of the fiber. Finally, the fiber temperature is related to the surrounding gas temperature through an energy balance on the fiber.

Vilimpoc and Goss ${ }^{1}$ first reported results using the TFP technique. They measured a line temperature profile at various heights above a $\mathrm{H}_{2}-\mathrm{N}_{2}$ jet diffusion flame. A rotating mirror traced the image of the fiber onto an InGaAs detector that was sensitive to radiation from 900 to $1600 \mathrm{~nm}$. The measurable filament temperature ranged from 1000 to $2370 \mathrm{~K}$ with a reported precision varying from $\pm 80 \mathrm{~K}$ at low temperatures to $\pm 8 \mathrm{~K}$ at high temperatures. The gas temperature profiles came from balancing convective and radiant energy (neglecting axial conduction along the fiber). Bedat et al. ${ }^{2}$ used an InSb (2.5 to $6.0 \mu \mathrm{m}$ sensitivity) detector to extend the low temperature range of TFP to approximately $550 \mathrm{~K}$. They used a narrow band filter at $3.9 \mu \mathrm{m}$ to limit the interference from flame radiation.

Pitts $^{3}$ used a cooled 16-bit camera (spectral response was not reported) to image a 15 micron $\mathrm{SiC}$ fiber in an acoustically phase-locked flickering (i.e. transient) laminar methane/air diffusion flame. He reported a measurement precision of $1.4 \pm 1 \mathrm{~K}$ for the filament temperature. The author, however, did not correct for radiative and conductive losses. Pitts acknowledged that the accuracy of the gas temperature measurement is considerably less than the precision without detailed knowledge of the flow velocities and chemical composition of the gas surrounding the $\mathrm{SiC}$ fiber.

*NASA Resident Research Associate at Glenn Research Center. 
$\mathrm{Ji}$ et $\mathrm{al}^{4}$ reported calibrating a $\mathrm{SiC}$ fiber temperature over a McKenna burner using an $\mathrm{InSb}$ detector in the wavelength range of 3300 to $4000 \mathrm{~nm}$. This work compared measured temperatures to values of the calculated adiabatic flame temperature. These values agreed to within $25 \mathrm{~K}$. This work also compared measured thermocouple temperatures at similar locations, which differed from the adiabatic temperature by as much as $150 \mathrm{~K}$. No account of radiative or conductive losses was reported in this paper.

The emphasis of this work was to apply the TFP technique to measure the gas temperature of a practical diffusion flame and compare these results to more traditional thermocouple measurements. The flame was a small $(1.3 \mathrm{~cm}$ height), axisymmetric, steady diffusion flame from a porous-metal wick burner. The fuel was methanol, burned in room air, and the resulting flame was very dim blue (nearly invisible to the eye). The dim, soot-free flame was necessary to eliminate broadband radiant emission from soot which greatly complicates temperature measurement using the TFP technique. The specific measurement techniques at different heights above the burner wick include:

1. A single-point fine-wire thermocouple (25.4 $\mu \mathrm{m}$ diameter wire with a $63.5 \mu \mathrm{m}$ bead diameter) measurement along the centerline of the flame.

1. A single point measurement using a $15 \mu \mathrm{m}$ diameter $\mathrm{SiC}$ fiber mounted horizontally across the flame. A spectrometer (sensitivity 585 to $1160 \mathrm{~nm}^{\dagger}$ ) detected emission from a small $\mathrm{SiC}$ portion intersecting along the centerline (i.e. the same location where the thermocouple bead was located previously).

2. The entire $\mathrm{SiC}$ fiber using a CCD camera sensitive between 200 and $1100 \mathrm{~nm}$.

We present comparisons of the resulting measurements from the above techniques. Additionally, emphasis is placed on estimating the uncertainty of the gas temperature when accounting for radiative and conductive losses in the measurements.

\section{Experiment}

The test apparatus consisted of a burner mounted on a vertical translation stage, a thermocouple, a silicon-carbide fiber ( $\mathrm{SiC})$, and various optical diagnostic/camera equipment (Figure 1). The thermocouple was parallel to and $3 \mathrm{~mm}$ below the $\mathrm{SiC}$

\footnotetext{
${ }^{\dagger}$ The actual spectral sensitivity was narrower than the detector capability due to the optics used in the experiment (discussed later).
}

fiber, with both perpendicular to the burner centerline. The thermocouple bead was on the burner centerline. Both the thermocouple and $\mathrm{SiC}$ fiber were under slight tension to prevent sagging when in the flame. The custom built burner consisted of a fuel reservoir penetrated by a cylindrical porous bronze metal wick. The bronze wick had a diameter of $3.25 \mathrm{~mm}$ and a wetted length of $6.2 \mathrm{~mm}$. The fuel was methanol, and the resulting diffusion flame, burning in room air, was very dim blue (nearly invisible to the eye). Figure 2 shows typical flame images taken with the CCD.

The test procedure was to traverse the flame vertically through the fixed thermocouple and $\mathrm{SiC}$ fiber arrangement. With the thermocouple initially at the wick surface and the $\mathrm{SiC}$ fiber $3 \mathrm{~mm}$ above the wick surface, the burner translated $15 \mathrm{~mm}$ downwards in $0.5 \mathrm{~mm}$ increments. At each increment, there were three separate but near simultaneous measurements: (1) a high-resolution, CCD camera image of the glowing $\mathrm{SiC}$ fiber; (2) a type-S thermocouple measurement of flame temperature, and (3) a spectrometer (sensitive from 585 to $1160 \mathrm{~nm}$ ) measurement of a point along the $\mathrm{SiC}$ fiber at the centerline of the flame. At each location, at least 1 minute passed prior to taking the measurements to ensure that the flame was steady.

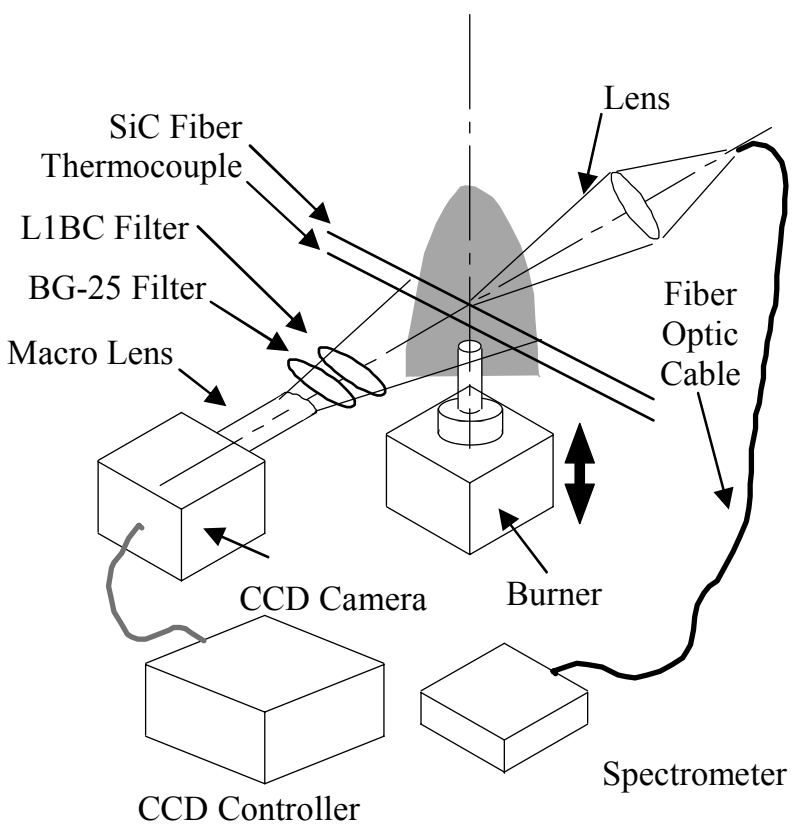

Figure 1. Schematic of experimental setup. 

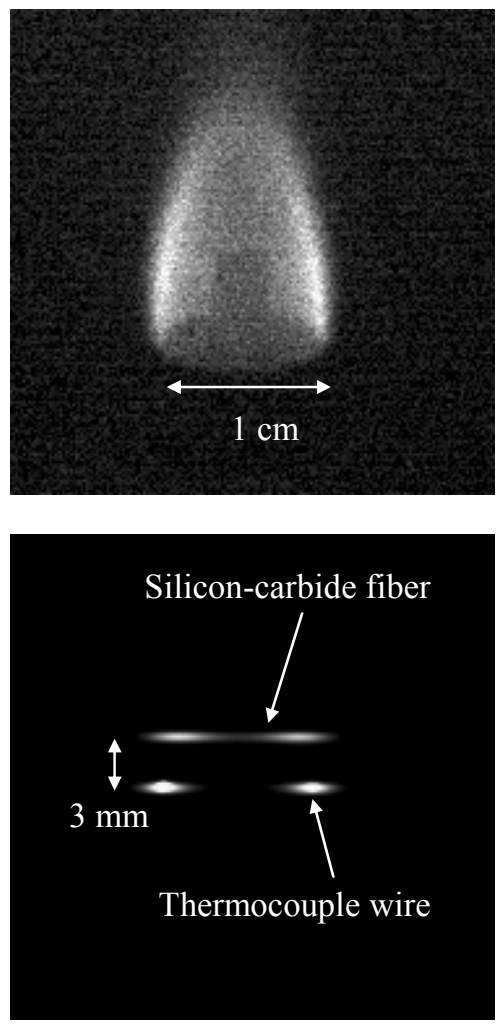

Figure 2. CCD camera images of a methanol/air diffusion flame. The upper image was taken just prior to testing (with image enhancement to bring out the flame) and the lower image was taken during testing with a $\mathrm{SiC}$ fiber and thermocouple placed in the flame. The $\mathrm{SiC}$ fiber emission and glowing thermocouple dominate the emission detected by the camera; hence, no flame is visible in the lower image.

\section{$\underline{\text { Experimental Apparatus }}$}

$\underline{\mathrm{SiC}}$

The SiC fiber used in these tests was manufactured by a polymer pyrolysis process. The fiber is homogeneously composed of ultra fine beta-SiC crystallites and an amorphous mixture of silicon (58\%), carbon $(21 \%)$, and oxygen $(11 \%)$. The fiber diameter was nominally $15 \mu \mathrm{m}$ but may vary from 12 to $18 \mu \mathrm{m}$ according to the manufacturer.

\section{Thermocouple}

The thermocouples were bare wire, type-S ( $\mathrm{Pt}-$ $\mathrm{Pt} / 10 \% \mathrm{Rh}$ ), with the bead of the thermocouple located on the centerline of the burner. We choose two thermocouple wire diameters, $76.2 \mu \mathrm{m}$ (0.003") and $25.4 \mu \mathrm{m}(0.001$ "), to show the effect of conductive losses along the fiber. The spherical thermocouple bead was 2.5 times the wire diameter as reported by the manufacturer.

A thermocouple signal conditioner (amplifier) and a data acquisition system measured the thermocouple voltage. The relationship between the thermocouple voltage and temperature is via a polynomial curve fit provided by the manufacturer.

\section{Spectrometer}

The spectrometer is sensitive to light in the wavelength range from $585 \mathrm{~nm}$ to $1160 \mathrm{~nm}$. The spectrometer has a 2048 element linear-detector array with each pixel digitized to 12 bits of resolution. The integration time (duration during which the light emission from the $\mathrm{SiC}$ was allowed to accumulate on the detector) varied between 60 to $200 \mathrm{msec}$.

The spectrometer measured the spectrum of light at a point on the $\mathrm{SiC}$ fiber directly above the thermocouple bead (i.e. along the flame centerline). A lens was in front of the open end of the fiber optic cable in order to focus the emission from a single point of the $\mathrm{SiC}$ fiber onto the end of the fiber optic cable (Figure 1).

\section{$\underline{\text { CCD camera }}$}

The camera uses a high-resolution (16 bit), thermoelectrically cooled, back-illuminated, charge-coupled device (CCD) array with a rectangular 330 by 1100 pixel array. The CCD has a spectral response from 200 to $1100 \mathrm{~nm}$. A $60 \mathrm{~mm}$ macro lens was in the front of the camera to image the fiber. The exposure time on the camera was $5 \mathrm{msec}$, the camera's shortest duration. An additional blue-glass filter (BG-25) reduced the intensity of the emission to prevent saturation of the CCD. A UV filter (L1BC) was part of the lens and thus accounted for in the analysis. A thermoelectric cooler kept the CCD array at $233 \mathrm{~K}$ to limit detector noise.

\section{$\underline{\text { Analysis }}$}

\section{Thermocouple}

The temperature of the thermocouple bead and actual temperature of the local gas are different and are related by a steady-state energy balance on the surface of the thermocouple bead (equation 1). ${ }^{5,6}$ Heat is added to the thermocouple bead through convection from the hot gases of the flame. Heat is lost from the thermocouple bead by radiation. Either a loss or gain of heat can occur by axial conduction along the thermocouple wire. In equation 1 , we assume the conduction term to be symmetric about the bead (i.e. on the burner centerline). Catalytic effects are neglected. 


$$
\begin{aligned}
& h A_{b}\left(T_{g}-T_{b}\right)-\varepsilon \sigma A_{b}\left(T_{b}{ }^{4}-T_{\infty}{ }^{4}\right) \\
& -\left.2 k_{w} A_{w}\left(\frac{d T_{w}}{d x}\right)\right|_{b}=0
\end{aligned}
$$

Equation 1 can be rearranged to solve for the gas temperature (equation 2).

$$
T_{g}=T_{b}+\frac{\varepsilon \sigma}{h}\left(T_{b}{ }^{4}-T_{\infty}{ }^{4}\right)+\left[\left.\left(\frac{2 k_{w} A_{w}}{h A_{b}}\right)\left(\frac{d T_{w}}{d x}\right)\right|_{b}\right]
$$

To compute the heat transfer coefficient, $h$, in equation 2, we used a Nusselt number for forced convection over a sphere at low Reynolds number (equation 3). ${ }^{7}$ The characteristic length for the Reynolds number is the thermocouple bead diameter (190 or $63 \mu \mathrm{m})$.

$$
\begin{gathered}
N u=2+\left(0.2 \times \operatorname{Re}^{0.82}\right)=\frac{h \times D_{b}}{k_{g}} \\
(\operatorname{Pr}=0.71, \quad 0.07 \leq \operatorname{Re} \leq 20) \quad\left(\operatorname{Re}=\frac{U \times D_{b}}{v_{g}}\right)
\end{gathered}
$$

The velocity used in the Reynolds number is from a scaling analysis for a candle flame which is appropriate for Grashof numbers $>1$ (equation 4$){ }^{8}$

$$
U=\sqrt{\frac{g H\left(\rho_{\infty}-\rho_{g}\right)}{\rho_{\text {avg }}}}
$$

$U$ is the maximum characteristic velocity for a flame of height $H$, the local density is $\rho_{H}$, and the mean density, $\rho_{\text {mean }}$, is the average value between the $\rho_{H}$ and the ambient density $\rho_{\infty}$. For our flame, the estimated characteristic velocity was $40 \mathrm{~cm} / \mathrm{s}$ which yielded $R e \sim$ 0.1 (using properties of air at the final film, or average, temperature).

The conductive term along the thermocouple wires (last term in equation 2) is difficult to calculate because it requires knowledge of the temperature gradient at the interface of the thermocouple bead and wire. This correction can be significant depending on the temperature gradient and thermocouple wire diameter. In many practical flame configurations, temperature gradients are steep. Thus, the only recourse to minimize conductive loss is to use small diameter thermocouples. We used two thermocouple wire diameters, 76.2 and $25.4 \mu \mathrm{m}$, during separate tests. Our results show that the gas temperature measured using the smaller diameter wire agreed better with the spectrometer data (presented later) compared to the tests with the larger diameter wire. We attribute this difference to the importance of conductive loss at larger thermocouple wire diameters and non-negligible temperature gradients; the latter due to slight variations in the position of the thermocouple bead with the centerline of the flame.

To evaluate the thermophysical properties in equations 2, 3, and 4, the composition and temperature of the gas must be known. Since we did not make measurements of the gas constituents surrounding the thermocouple, we must make an assumption regarding the gas composition. In this analysis, we assumed that the surrounding gas is air and values for thermophysical properties were from Incropera \& DeWitt (1990). ${ }^{9}$ The thermophysical properties are evaluated at the film temperature, that is the average value between the thermocouple and gas temperature. Since the gas temperature is unknown, the gas temperature must be deduced in an iterative fashion. The total emissivity of the bare wire thermocouple is a function of temperature (and oxidation level of the surface) and ranged between $0.18<\varepsilon<0.24$. $^{10}$ Although oxidation effects may change the emissivity of the thermocouple especially during exposure to flame conditions, we neglect the effect of thermocouple oxidation in the analysis. Figure 3 shows the results of the thermocouple measurement (25.4 $\mu \mathrm{m}$ diameter wire) and the calculated gas temperature around the thermocouple along the centerline of the flame.

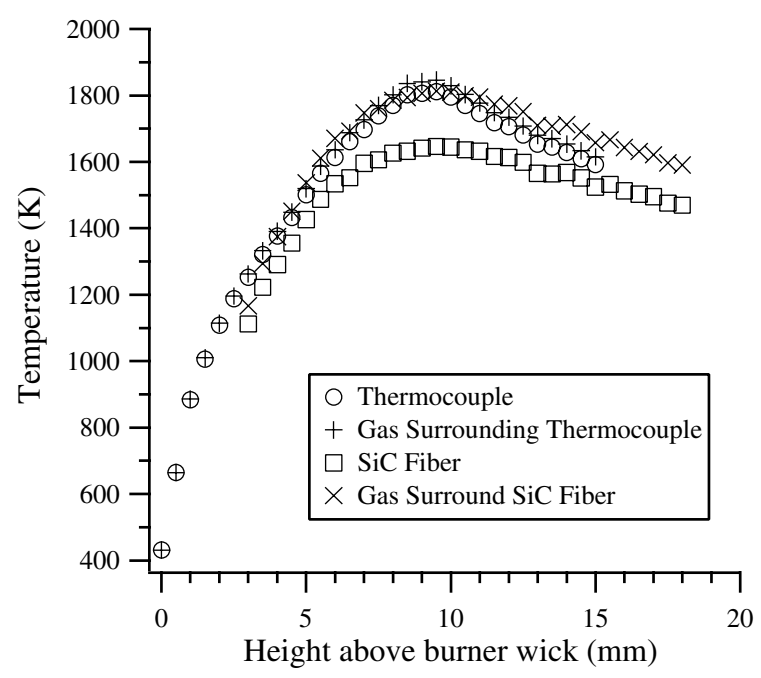

Figure 3. Temperature measurements along the centerline of the burner as a function of height using a thermocouple and spectrometer / SiC fiber TFP technique. 


\section{Spectrometer}

The spectrometer measured the spectral emission from a point on the $\mathrm{SiC}$ fiber located on the centerline of the flame. Equations 5 and 6 show the total spectral emission, $\mathrm{I}_{\text {Total }}$, where the $\mathrm{SiC}$ emission is equal to the emission of a black body at the fiber temperature, $\mathrm{I}_{\mathrm{BB}}(\lambda, T)$, times the emissivity of the fiber. Taking measurements of just the blue flame produced no appreciable signal on the spectrometer, consequently we were able to neglect the emission of the flame in our analysis. The spectrometer does produce, however, a signal even when no ambient radiation is allowed to reach the detector (e.g. covered detector). This "dark signal" is measured prior to each test and subtracted from the $\mathrm{SiC}$ signal.

$$
\begin{gathered}
I_{\text {Total }}(\lambda, T)=\left[\varepsilon(\lambda) \times I_{B B}(\lambda, T)+I_{\text {flame }}(\lambda, T)\right] \\
I_{B B}(\lambda, T)=\frac{C_{1}}{\pi \lambda^{4}\left[\exp \left(\frac{C_{2}}{\lambda T}\right)-1\right]} \\
C_{1}=1.884 \times 10^{27}\left(\frac{\text { photons } \times \mu m^{3}}{m^{2} \times s}\right) \\
C_{2}=14387.69(\mu m \times K)
\end{gathered}
$$

The emission measured by the spectrometer is different than the total emission leaving the $\mathrm{SiC}$ fiber (and flame). The difference results from attenuation of the light signal through the atmosphere, various optics in the system prior to reaching the detector, and the quantum efficiency of the detector. The final signal on the detector is converted to a voltage which is then converted to counts in the A/D converter. The detector signal, $R(\lambda)$, can be expressed mathematically as in equation 7 where $\lambda$ is the wavelength of light, $T$ is the temperature of the $\mathrm{SiC}, \mathrm{G}$ corresponds to the detected photons to voltage conversion, $\mathrm{QE}(\lambda)$ is the spectral quantum efficiency of the detector, and $\operatorname{Loss}(\lambda)$ is the spectral attenuation of the light due to the optics. Following the procedure of Miller ${ }^{11}$, a function, $S(\lambda)$, relates the spectral sensitivity of the detector and optics to the incoming radiation (equation 8). Thus, a blackbody intensity profile (equation 9) comes from rearranging equations 7 and 8 .

$$
\begin{gathered}
R(\lambda, T)=G \times[Q E(\lambda) \times \operatorname{Loss}(\lambda)] \times \varepsilon(\lambda) \times I_{B B}(\lambda, T) \\
S(\lambda)=\frac{1}{[Q E(\lambda) \times \operatorname{Loss}(\lambda)]} \\
I_{B B}(\lambda, T)=\frac{R(\lambda, T) \cdot S(\lambda)}{G \cdot \varepsilon(\lambda)}
\end{gathered}
$$

The data show that the emissivity of $\mathrm{SiC}$ is relatively uniform in the wavelength range of the spectrometer and the temperature range of the flame. ${ }^{12}$ Also, the conversion from detected photons to voltage is linear, hence, the variable $G$ is constant. Since the emissivity and $\mathrm{G}$ are independent of $\lambda$ and $\mathrm{T}$, they can be eliminated from the equation by normalizing equation 7 by values at a normalization wavelength, $\lambda_{0}$ (equation 10). The normalized functions (denoted by a bar) can be rearranged to solve for the blackbody intensity as shown in equation 11 .

$$
\begin{gathered}
\frac{R(\lambda, T)}{R\left(\lambda_{0}, T\right)}=\left(\frac{Q E\left(\lambda_{0}\right) \cdot \operatorname{Loss}\left(\lambda_{0}\right)}{Q E(\lambda) \cdot \operatorname{Loss}(\lambda)}\right)\left(\frac{I_{B B}(\lambda, T)}{I_{B B}\left(\lambda_{0}, T\right)}\right) \\
\overline{I_{B B}}(\lambda, T)=\bar{S}(\lambda) \times \bar{R}(\lambda, T)
\end{gathered}
$$

A custom computer program calculated the temperature of a blackbody that best matches (in a least-squares sense) the measured spectral distribution according to equation 11 . To do this calculation, the sensitivity function of our spectrometer / optical system was determined using a blackbody calibration source at three temperatures $\left(800,900\right.$, and $\left.1000{ }^{\circ} \mathrm{C}\right)$. The sensitivity function was the same (within the uncertainty of the detector) at each temperature (as expected since it should only be a function of wavelength). Although the spectrometer is sensitive to light between 585 and $1160 \mathrm{~nm}$, we used data only in the range from 766 to $940 \mathrm{~nm}$. Outside this range, the signal to noise ratio was quite high (particularly near the extremes of the detector sensitivity). The normalization wavelength was $894 \mathrm{~nm}$ which corresponds to the most intense signal on the spectrometer. The selection of the normalization wavelength does not affect the results so long as there is a large signal to noise ratio at the wavelength of choice. Figure 4 shows the sensitivity function as a function of wavelength, normalized by the signal at $894 \mathrm{~nm}$.

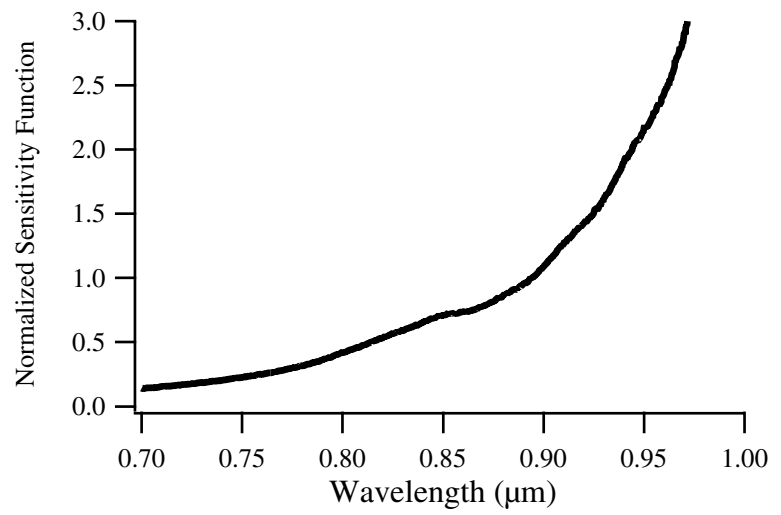

Figure 4. Sensitivity function (normalized at $894 \mathrm{~nm}$ ) for the spectrometer as a function of wavelength from blackbody calibration. 
The gas temperature surrounding the $\mathrm{SiC}$ is obtained in a similar fashion to the calculation presented for the thermocouple. Performing an energy balance on a differential axial element of the $\mathrm{SiC}$ fiber yields equation 12. As with the thermocouple, the $\mathrm{SiC}$ absorbs heat from convection, loses heat from radiation, and loses or gains heat by axial conduction along the fiber.

$$
\begin{aligned}
& h\left(T_{g}-T_{f}\right)-\varepsilon \sigma\left(T_{f}{ }^{4}-T_{\infty}{ }^{4}\right) \\
& -\frac{D_{f}}{4} \frac{d}{d x}\left(k_{f} \frac{d T_{f}}{d x}\right)=0
\end{aligned}
$$

Based on temperature profiles obtained from the CCD camera (see for example, Figure 7, which will be discussed later), we were able to estimate the temperature gradients along the $\mathrm{SiC}$ fiber. Based on the maximum temperature gradients and the small fiber diameter, we calculated the conductive correction to be on the order of $\pm 1 \mathrm{~K}$. Thus we neglect axial conduction in equation 12 and rearrange the equation to solve for the gas temperature just using a radiation correction (equation 13).

$$
T_{g}=T_{f}+\frac{\varepsilon \sigma}{h}\left(T_{f}^{4}-T_{\infty}^{4}\right)
$$

The heat transfer coefficient, $h$, comes from a Nusselt number correlation for forced convection over a cylinder (equation 14). ${ }^{13,14}$ A typical Reynolds number for our problem based on the $\mathrm{SiC}$ fiber diameter, $\mathrm{D}_{f}$, was $\sim 0.01$.

$$
\begin{aligned}
& N u=\left(0.42 \times \operatorname{Pr}^{0.2}\right)+\left(0.57 \times \operatorname{Re}^{0.5} \times \operatorname{Pr}^{0.33}\right) \\
& =\frac{h \times D_{f}}{k_{g}} \\
& (\operatorname{Pr}=0.71, \quad 0.01 \leq \operatorname{Re} \leq 10,000) \quad\left(\operatorname{Re}=\frac{U \times D_{f}}{v_{g}}\right)
\end{aligned}
$$

Figure 3 (shown previously) displays the results of the temperature calculation of the $\mathrm{SiC}$ fiber using the spectrometer and the estimate of the surrounding gas temperature along the centerline of the flame.

\section{$\underline{\text { CCD camera }}$}

The CCD imaged the entire burner, flame, thermocouple, and $\mathrm{SiC}$ fiber. The light from the $\mathrm{SiC}$ and thermocouple dominated the image (Figure 2) although the flame radiation was detectable and produced a small signal near the flame (not apparent in the right hand side of Figure 2). Additionally, the CCD camera produced a signal ("dark current") even when no light was incident on the detector (e.g. covered) although this effect was minimized by the thermoelectric cooler of the detector. Both the flame signal and dark signal were subtracted from the measured intensities of the camera on a pixel by pixel basis.

We relate the measured intensity at each pixel location along the length of the fiber (with a resolution of approximately 0.14 millimeters per pixel) to the fiber temperature. The $\mathrm{SiC}$ fiber diameter $(\sim 0.015 \mathrm{~mm})$ is smaller than the resolution of a single pixel in the image plane by an order of magnitude. The image of the glowing SiC fiber, however, produced an apparent fiber diameter that was almost 5 pixels wide $(\sim 0.7 \mathrm{~mm})$. This "blooming" phenomenon is visually apparent to the naked eye when observing the glowing $\mathrm{SiC}$ fiber. Although the physical mechanism, whether optical or in the electronics of the detector (or both), is not clear, the blooming effect must be accounted for in the analysis. This was done using two methods, a column sum method and a maximum intensity method. For the column sum method, all the intensities in each vertical column (y-direction) of a region surrounding the fiber were summed to get a intensity profile (x-direction) along the fiber. The region around the fiber consisted of 10 pixels above and below the centerline of the $\mathrm{SiC}$ fiber. The maximum method used the maximum intensity of each column in the same region to find a horizontal intensity profile along the fiber. These two techniques produced almost identical results; therefore, we present only the results of the maximum method.

The measured intensity at each pixel corresponds to the integrated effect of all incident radiation to which the detector (pixel) is sensitive. The incident radiation comes from a gray body emitter (the $\mathrm{SiC}$ fiber) and is attenuated by various optical components before reaching the detector. The detector responds differently to various wavelengths of light (i.e. quantum efficiency, which is the fraction of detected photons per incident photons on the detector).

Mathematically, the detected signal is proportional to the integral across the detector spectral sensitivity of the product of the emission of the $\mathrm{SiC}$ fiber, $\varepsilon(\lambda) \cdot I_{B B}(\lambda, T)$; the attenuation, Loss $(\lambda)$; and the quantum efficiency, $Q E(\lambda)$. Multiplying the integral by the exposure time, $\Delta t$; the pixel area, $A$; and a conversion factor from charge to counts, $G$, yields the detected signal per pixel in units of counts, $P(T)$ as shown in equation 15 . For this analysis, $\varepsilon, G, A$, and $\Delta t$ are assumed to be constant. 


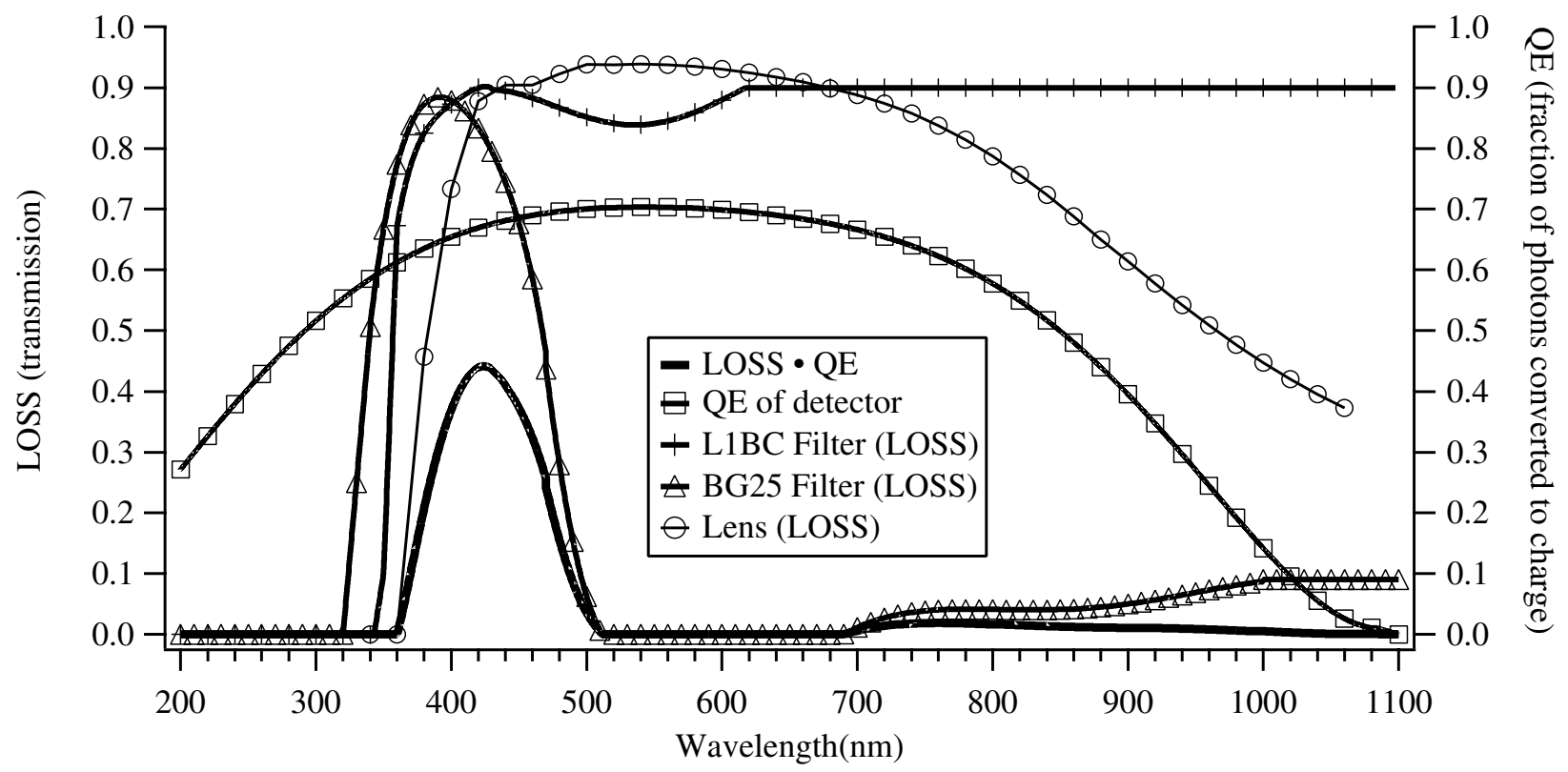

Figure 5. The optical transmissive properties of the components used to image the SiC fiber, the quantum efficiency of the detector, and their product as a function of wavelength.

$$
\begin{aligned}
& P(T)= \\
& G \cdot \Delta T \cdot A \int_{\lambda_{1}}^{\lambda_{2}}\left[\operatorname{Loss}(\lambda) \cdot Q E(\lambda) \cdot \varepsilon(\lambda) \cdot I_{B B}(\lambda, T)\right] d \lambda
\end{aligned}
$$

The CCD camera is sensitive to light between $\lambda_{1}=200 \mathrm{~nm}$ and $\lambda_{2}=1100 \mathrm{~nm}$. The loss function is the product of the transmission efficiencies of the optical elements in the system (filters and lenses, see Figure 1). Figure 5 shows the manufacturer's transmission efficiencies for all of the optical elements in the system and the calculated overall loss function versus $\lambda$. The unknown quantity, $G$ (as well as $\varepsilon, A$, and $\Delta t$ ), drops out of equation 15 by taking the ratio of the CCD counts at any arbitrary temperature, $P(T)$, to the counts at a known temperature, $P\left(T_{0}\right)$ (equation 16).

$$
\frac{P(T)}{P\left(T_{0}\right)}=\frac{\int_{\lambda_{1}}^{\lambda_{2}}\left[\operatorname{Loss}(\lambda) \times Q E(\lambda) \times I_{B B}(\lambda, T)\right] d \lambda}{\int_{\lambda_{1}}^{\lambda_{2}}\left[\operatorname{Loss}(\lambda) \times Q E(\lambda) \times I_{B B}\left(\lambda, T_{0}\right)\right] d \lambda}
$$

For this analysis, the unknown reference temperature, $T_{0}$, was obtained from the spectrometer temperature measurement taken simultaneously with the CCD of a point on the SiC fiber at the centerline of the flame. Using the maximum method described earlier, the CCD counts at the pixel location corresponding to the intersection of the $\mathrm{SiC}$ with the flame centerline was used to obtain $P\left(T_{0}\right)$. Knowing $T_{0}$ and $P\left(T_{0}\right)$, we generate a curve relating $P(T)$ to $T$ by numerically integrating equation 16 . Figure 6 shows the various curves generated by the numerical integration over several tests (each curve corresponding to a different height above the burner). While the camera precision is less than $1 \mathrm{~K}(20000$ discretization levels over an $800 \mathrm{~K}$ temperature range), the calculated fiber temperature varies as high as $\pm 38 \mathrm{~K}$ from the mean value for a given count value (Figure 6). The uncertainty in the measurement accuracy arises from variations in pixel response, optical transmission properties, fiber emissivity, and the reference temperature, $T_{0}$.

For each image from the CCD, we converted all the pixel count (maximum) values to temperatures using the calibration curve generated for that particular height above the burner yielding a one dimensional temperature profile along the $\mathrm{SiC}$ fiber. Figure 7 shows the temperature profile of the $\mathrm{SiC}$ fiber at $5.5 \mathrm{~mm}$ above the burner surface. The gas temperature profile along the $\mathrm{SiC}$ fiber is found using the same energy-balance technique as for the spectrometer measurement. Using the data from the various heights above the burner, we generated a $2 \mathrm{D}$ contour map of the temperature profiles of the gas above the wick of the burner (Figure 8). For the gas temperature calculation, we neglect a conductive losses based on estimates that the maximum conduction correction is roughly $\pm 1 \mathrm{~K}$ as discussed 
previously. The characteristic velocity of the flame was the velocity for the entire length of the fiber. This approximation is justifiable since the gas temperature shows only small changes with large variations of velocity. The uncertainty in the gas temperature calculation are the topic of the next section.

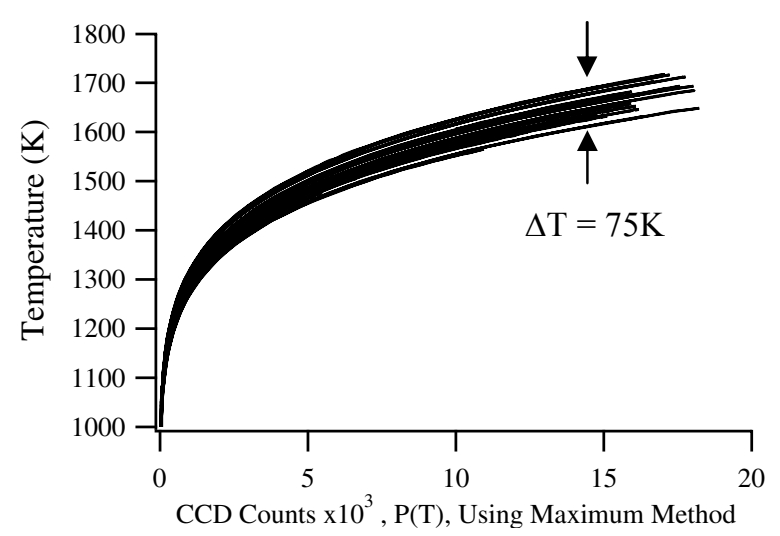

Figure 6. Temperature vs. count values for the CCD camera. Each curve represents the data obtained for each height above the burner. The variation in the curves shows the uncertainty in this method can be as high as $\pm 38 \mathrm{~K}$.

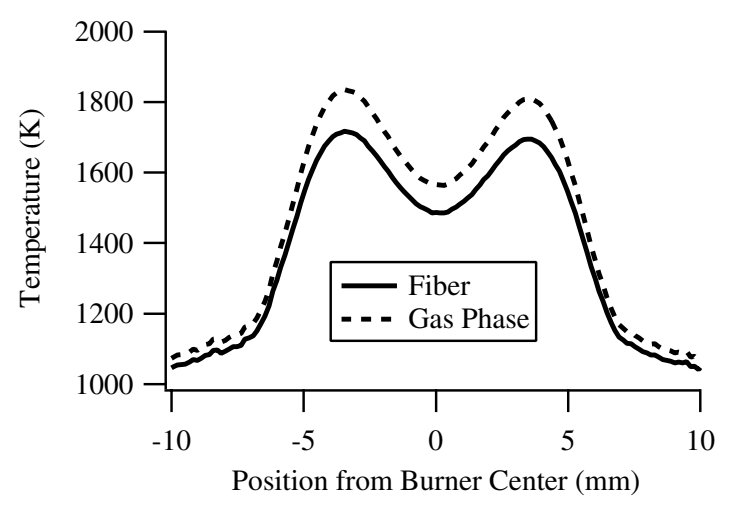

Figure 7. SiC fiber and surrounding gas temperature at a height of $5.5 \mathrm{~mm}$ above the burner wick computed from CCD camera images of the $\mathrm{SiC}$ fiber placed in the flame.

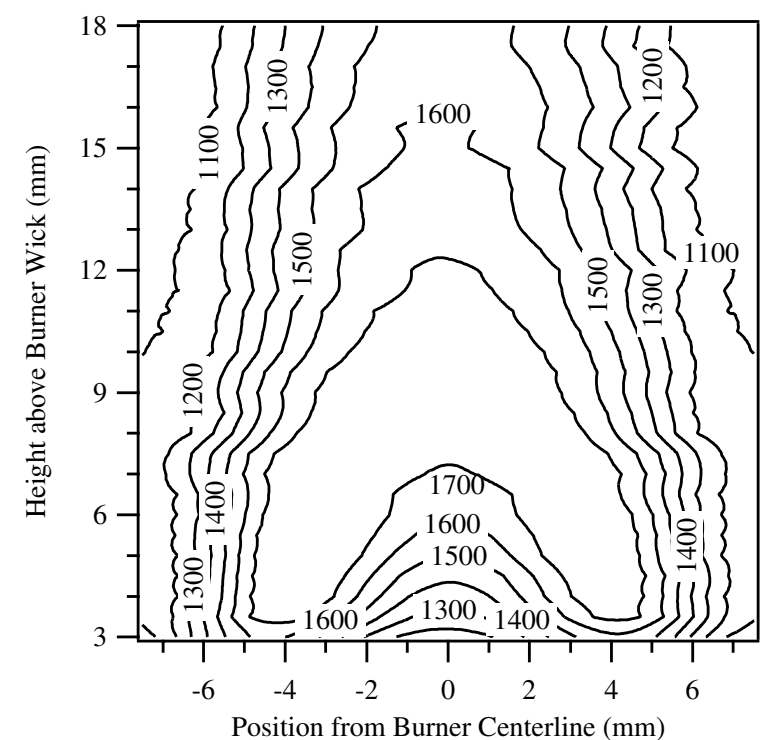

Figure 8. 2D gas temperature contours for a methanol/air diffusion flame. The plot is generated from the 1D temperature profiles obtained using TFP (CCD camera) at $0.5 \mathrm{~mm}$ increments above the wick surface.

\section{Uncertainty in Gas Temperature Calculation}

The relationship between the fiber temperature (obtained using TFP) and the gas temperature comes from an energy balance on the fiber. This relationship includes the convective heat transfer between the fiber and the gas, radiative loss from the fiber to the ambient, and conductive energy transport along the fiber. The $\mathrm{SiC}$ is not catalytically active, so we neglect catalytic effects. Further, we neglect conductive energy loss along the fiber, which we estimate to be small $(\sim 1 \mathrm{~K})$. Equation 13 shows the resulting relationship between the gas and fiber temperatures. Because we do not directly measure the gas temperature it is important to consider the sources of potential error and their influence on the accuracy of the gas temperature measurement.

The major sources of uncertainty in gas temperature $\left(T_{g}\right)$ are in the determination of the fiber temperature $\left(T_{f}\right)$, the emissivity $(\varepsilon)$ of the fiber, and the convective heat transfer coefficient $(h)$. The heat transfer coefficient comes from Nusselt number $(\mathrm{Nu})$ correlations for heat transfer which is related to the fiber diameter $\left(D_{f}\right)$ as shown in equation 14. There exist several sources of uncertainty in the determination of $N u$. First, these correlations may not be valid at the scale (fiber diameter and potentially large temperature gradients along the fiber) we are using them; they are bulk correlations for heat 
transfer. Second, the correlation requires knowledge of the Reynolds Number (Re), which in turn requires knowledge of the velocity perpendicular to the fiber. In the present paper, we use an estimate of this velocity from buoyant scaling arguments. Finally, both $R e$ and $N u$ require the thermo-physical properties of the convecting gas. These properties are functions of both temperature and gas composition, both of which are estimates.

As for the other variables, $D_{f}$ can vary considerably (the manufacturer quotes 12 to $18 \mu \mathrm{m}$ ), and $\varepsilon$ depends on the oxidative coating that forms on the fiber (and therefore the age of the fiber). Finally, there is obviously uncertainty in the determination of the actual fiber temperature. Figure 9 shows how variations in each of these parameters effects the gas temperature. This figure uses a fiber temperature of $1800 \mathrm{~K}$ measured near the tip of the flame for reference, which results in a gas temperature of $1914 \mathrm{~K}$. The figure shows the absolute change in gas temperature (referenced to $1914 \mathrm{~K}$ ) as a function of the percent change in $T_{\text {fiber }}, N u, D_{f}$, and $\varepsilon$ from their measured or assumed values.

Figure 9 shows, as one would expect, that there is a nearly one to one correlation between uncertainties in fiber temperature and errors in the assumed gas temperature (the slight deviation from one-to-one results from the radiation correction). Fortunately, as Figure 9 shows, there is a far smaller dependence on the values of $N u, \mathrm{D}_{f}$, and $\varepsilon$. In fact, variations as much as 30 percent in these variables results in errors in gas temperatures of less than $50 \mathrm{~K}$

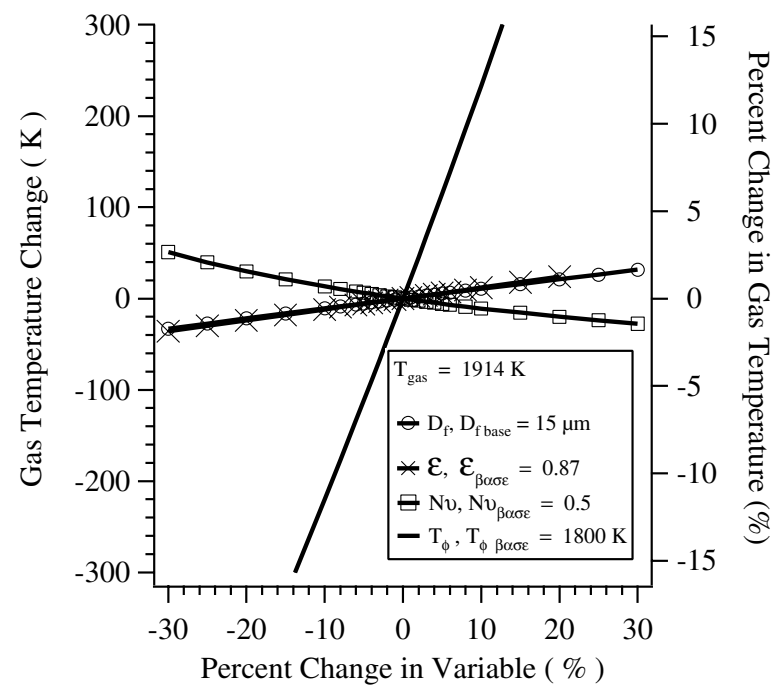

Figure 9. Variation in gas temperature calculation with changes in fiber diameter, fiber emissivity, Nusselt number, and fiber temperature.
(2.6\%). Therefore, while there is a large uncertainty regarding the exact and appropriate values of $\mathrm{D}_{f}, N u$ and $\varepsilon$, the resulting errors in gas temperature are relatively small.

\section{Conclusions}

In the present work, we compared single point flame temperature measurements using thin-filament pyrometry (TFP) and thermocouples. The data was from vertically traversing a thermocouple and a silicon-carbide ( $\mathrm{SiC}$ ) fiber through a methanol/air diffusion flame of a porous-metal wick burner. One TFP technique used a spectrometer which measured the radiative emission at a point on the $\mathrm{SiC}$ along the burner centerline. The relationship between the emission and fiber temperature was from gray body theory and the measured response of the spectrometer based on blackbody calibration. The relationship between the gas temperature and the $\mathrm{SiC}$ fiber (or thermocouple) temperature comes from an energy balance on the fiber. The results showed that the gas temperature using the TFP technique agreed with the thermocouple measurements $(25.4 \mu \mathrm{m}$ diameter wire) within $3.5 \%$ for temperatures above $1200 \mathrm{~K}$. The agreement was not as good with larger diameter thermocouples indicating the increased importance of conductive losses with larger thermocouple wires.

Additionally, we imaged the entire $\mathrm{SiC}$ fiber while it was embedded in the flame using a high resolution CCD camera which is sensitive to UV and visible light. The light emission from the heated $\mathrm{SiC}$ fiber dominated the image. We related the maximum intensity level along the fiber length (with a spatial resolution of $0.14 \mathrm{~mm}$ ) to the temperature. This relationship comes from an integration across the detector's spectral response of the incident radiation. The calculation required a single-point temperature calibration which we obtained from the single-point spectrometer measurement which were done simultaneously. We made estimates of the gas temperature surrounding the fiber using an energybalance and appropriate heat-transfer correlations. From the data, we generated 1D temperature profiles at various heights above the burner wick. This temperature measurement technique, while having a precision of less than $1 \mathrm{~K}$, showed data scatter as high as $\pm 38 \mathrm{~K}$.

Finally, we discuss the major sources of uncertainty in gas temperature. The largest uncertainty in gas temperature comes from the fiber temperature itself showing almost a one to one variation. There is a far smaller dependence on the values of heat transfer coefficient (Nusselt number), fiber diameter, and emissivity. In fact, variations as much as 30 percent in these variables results in errors in gas temperatures of less than $50 \mathrm{~K}(2.6 \%)$. 


\section{Nomenclature}

h heat transfer coefficient

$\mathrm{H} \quad$ flame characteristic length $(1.3 \mathrm{~cm})$

A pixel area

$\mathrm{A}_{b} \quad$ thermocouple bead surface area

$\mathrm{A}_{w} \quad$ thermocouple wire cross-sectional area

D diameter

$\mathrm{R} \quad$ spectrometer signal

$\mathrm{G}$ linear conversion of detected photons to volts

Loss spectral attenuation by optical elements

$\mathrm{S} \quad$ detector spectral sensitivity function

QE detector quantum efficiency

$\mathrm{T}$ temperature

I radiant intensity

$\mathrm{k}$ thermal conductivity

$\mathrm{x}$ axial coordinate along fiber and thermocouple

$\mathrm{Nu} \quad$ Nusselt number

Re Reynolds number

Pr Prandtl number

$\mathrm{P} \quad$ detected pixel counts

g gravitational acceleration

$\rho$ density

U characteristic buoyant velocity $(\sim 44 \mathrm{~cm} / \mathrm{s})$

$\varepsilon \quad$ emissivity

$\sigma \quad$ Stefan-Boltzmann Constant

$\lambda \quad$ wavelength

$v \quad$ kinematic viscosity of the gas

\section{$\underline{\text { subscripts }}$}

$w \quad$ thermocouple wire

$B B \quad$ black body

$b \quad$ thermocouple bead

$g \quad$ local gas

$f \quad$ silicon-carbide fiber

0 normalization value

$\infty \quad$ ambient or surrounding conditions

avg average or mean value

\section{References}

1. Vilimpoc, V. and Goss, L.P. (1988). SiC-Based Thin-Filament Pyrometry: Theory and Thermal Properties. Twenty-second Symposium (International) on Combustion / The Combustion Institute, Pittsburgh, PA, 907.

2. Bedat B., Giovanninni, A., and Pauzin, S. (1994). Thin filament infrared pyrometry: instantaneous temperature profile measurements in a weakly turbulent hydrocarbon premixed flame. Experiments in Fluids, 17, 397.
3. Pitts, W.M. Thin-Filament Pyrometry in Flickering Laminar Diffusion Flames. (1996). Twenty-sixth Symposium (International) on Combustion / The Combustion Institute, Pittsburgh, PA, 1171.

4. Ji, J., Sivathanu, Y.R., and Gore, J.P. (1999). Thin Filament Spectral Pyrometry for Flame Temperature Measurements. First Joint Meeting of the U.S. Sections of the Combustion Institute: Western States, Central States, Eastern States, Washington, D.C., 184.

5. Bradley, D. and Matthews, K.J. (1968). Measurement of High Temperatures with Fine Wire Thermocouples. Journal of Mechanical Engineering Science, 10, 299.

6. Govatzidakis, G.J. (1993). Thermocouple Thermometry in Soot Bearing Flames, M.S. Thesis, Brown University.

7. Yelistratov, S.L. (1984). Experimental investigation of forced-convection heat transfer to a sphere at low Reynolds numbers. Heat Transfer - Soviet Research, 16(6), 71.

8. Ross, H.D., Dietrich, D.L., and T'ien, J.S. (1990). Observations of Candle Flames in Low Gravity and Low Pressure. Fall Technical Meeting of the Eastern States Section of the Combustion Institute, Orlando, FL.

9. Incropera, F.P. and De Witt, D.P. (1990). Fundamentals of Heat and Mass Transfer $\left(3^{\text {rd }}\right.$ Ed.). John Wiley and Sons, Inc. New York, NY.

10. Bradley, D. and Entwistle, A.G. (1968). Determination of the emissivity, for total radiation, of small diameter platinum-10\% rhodium wires in the temperature range 600$1450^{\circ}$ C. British Journal of Applied Physics, 12, 708.

11. Miller, F.J. (2000). Multi-wavelength Optical Pyrometry for Solid-Phase Temperature Measurements. Spring Technical Meeting of the Western States Section of the Combustion Institute.

12. Touloukian, Y.S. and Makita, T. (1970). Thermal Radiative Properties: Non-Metallic Solids. Thermophysical Properties of Matter, 8, IFI / Plenum, New York, NY.

13. Kramers, H. (1946). Physica, 12, 61.

14. Hinze, J. (1975). Turbulence ( $2^{\text {nd }}$ Ed). McGrawHill Series in Mechanical Engineering, New York, NY. 88. 

Public reporting burden for this collection of information is estimated to average 1 hour per response, including the time for reviewing instructions, searching existing data sources, gathering and maintaining the data needed, and completing and reviewing the collection of information. Send comments regarding this burden estimate or any other aspect of this collection of information, including suggestions for reducing this burden, to Washington Headquarters Services, Directorate for Information Operations and Reports, 1215 Jefferson Davis Highway, Suite 1204, Arlington, VA 22202-4302, and to the Office of Management and Budget, Paperwork Reduction Project (0704-0188), Washington, DC 20503.

\begin{tabular}{|l|l|l}
\hline 1. AGENCY USE ONLY (Leave blank) & $\begin{array}{c}\text { 2. REPORT DATE } \\
\text { February } 2003\end{array}$ & $\begin{array}{r}\text { 3. REPORT TYPE AND DATES COVERED } \\
\text { Technical Memorandum }\end{array}$ \\
\hline
\end{tabular}

\section{TITLE AND SUBTITLE}

5. FUNDING NUMBERS

Comparisons of Gas-Phase Temperature Measurements in a Flame Using

Thin-Filament Pyrometry and Thermocouples

6. AUTHOR(S)

Peter Struk, Daniel Dietrich, Russell Valentine, and Ioan Feier

WBS-22-101-32-06

7. PERFORMING ORGANIZATION NAME(S) AND ADDRESS(ES)

National Aeronautics and Space Administration

John H. Glenn Research Center at Lewis Field

Cleveland, Ohio 44135-3191

8. PERFORMING ORGANIZATION

REPORT NUMBER

E-13749

\section{SPONSORING/MONITORING AGENCY NAME(S) AND ADDRESS(ES)}

National Aeronautics and Space Administration

Washington, DC 20546-0001

10. SPONSORING/MONITORING

AGENCY REPORT NUMBER

NASA TM-2003-212096

AIAA-2003-853

\section{SUPPLEMENTARY NOTES}

Prepared for the 41st Aerospace Sciences Meeting and Exhibit sponsored by the American Institute of Aeronautics and Astronautics, Reno, Nevada, January 6-9, 2003. Peter Struk and Daniel Dietrich, NASA Glenn Research Center; Russell Valentine, Case Western Reserve University, Cleveland, Ohio 44106; and Ioan Feier, Case Western Reserve University, Cleveland, Ohio 44106, and NASA Resident Research Associate at Glenn Research Center. Responsible person, Peter Struk, organization code 6711, 216-433-5948.

12a. DISTRIBUTION/AVAILABILITY STATEMENT

12b. DISTRIBUTION CODE

Unclassified - Unlimited

Subject Category: 70

Distribution: Nonstandard

Available electronically at http://gltrs.grc.nasa.gov

This publication is available from the NASA Center for AeroSpace Information, 301-621-0390.

13. ABSTRACT (Maximum 200 words)

Less-intrusive, fast-responding, and full-field temperature measurements have long been a desired tool for the research community. Recently, the emission of a silicon-carbide ( $\mathrm{SiC}$ ) fiber placed in a flowing hot (or reacting) gas has been used to measure the temperature profile along the length of the fiber. The relationship between the gas and fiber temperature comes from an energy balance on the fiber. In the present work, we compared single point flame temperature measurements using thin-filament pyrometry (TFP) and thermocouples. The data was from vertically traversing a thermocouple and a $\mathrm{SiC}$ fiber through a methanol/air diffusion flame of a porous-metal wick burner. The results showed that the gas temperature using the TFP technique agreed with the thermocouple measurements ( $25.4 \mathrm{~mm}$ diameter wire) within 3.5 percent for temperatures above $1200 \mathrm{~K}$. Additionally, we imaged the entire $\mathrm{SiC}$ fiber (with a spatial resolution of $0.14 \mathrm{~mm}$ ) while it was in the flame using a high resolution CCD camera. The intensity level along the fiber length is a function of the temperature. This results in a one-dimensional temperature profiles at various heights above the burner wick. This temperature measurement technique, while having a precision of less than $1 \mathrm{~K}$, showed data scatter as high as $\pm 38 \mathrm{~K}$. Finally, we discuss the major sources of uncertainty in gas temperature measurement using TFP.

\section{SUBJECT TERMS}

Temperature measurement; Gas temperature; Radiation pyrometers; Thermocouples;

Silicon carbides; CCD cameras

\begin{tabular}{|c|c|c|}
\hline $\begin{array}{c}\text { 17. SECURITY CLASSIFICATION } \\
\text { OF REPORT } \\
\text { Unclassified }\end{array}$ & $\begin{array}{c}\text { 18. SECURITY CLASSIFICATION } \\
\text { OF THIS PAGE } \\
\text { Unclassified }\end{array}$ & $\begin{array}{c}\text { 19. SECURITY CLASSIFICATION } \\
\text { OF ABSTRACT } \\
\text { Unclassified }\end{array}$ \\
\hline
\end{tabular}

NSN 7540-01-280-5500

\begin{tabular}{|l|} 
15. NUMBER OF PAGES \\
16 \\
\hline 16. PRICE CODE \\
20. LIMITATION OF ABSTRACT \\
\end{tabular}

Standard Form 298 (Rev. 2-89) 